Vol. 56 (2019), No. 2, 239-252

\title{
Effect of cultivar, crop management, location and growing season on the grain yield of triticale
}

\author{
Adriana Derejko, Marcin Studnicki \\ Department of Experimental Design and Bioinformatics, Warsaw University of Life Sciences - \\ SGGW, Nowoursynowska 159, Warsaw, Poland, adriana_derejko@sggw.pl
}

SUMMARY

\begin{abstract}
Triticale (Triticosecale Wittmack) is obtained through the crossing of wheat (Triticum ssp.) and rye (Secale cereale L.) and is characterized by high yield potential, good health and grain value, and high tolerance to biotic and abiotic stress. Poland is a very important region for progress in triticale breeding, since it is home to most cultivars, and numerous genetic studies on triticale have been carried out. Despite the tremendous interest in triticale among both breeders and researchers, there are no studies assessing the adaptation of cultivars to environmental conditions across growing seasons. This study was conducted to investigate the influence of cultivar, management, location and growing season on grain yield. At the same time, this approach provides a new way to determine whether there is any dependency between the eight seasons, and to find the cause of the yield response to environmental conditions in a given growing season.
\end{abstract}

Keywords: triticale, cultivar and environmental interaction, growing seasons, linear mixed models

\section{Introduction}

Triticale (Triticosecale Wittmack) is a hybrid crop that is obtained through the crossing of wheat (Triticum ssp.) and rye (Secale cereale L.). Its purpose is to produce cereals combining the beneficial qualities of the two crossed species. Triticale is characterized by high yield potential, as well as good health and grain value. Furthermore, it offers high tolerance to biotic and abiotic stress (Ammar et al. 2004). Triticale has a broad range of applications. Its grain is mainly used for animal feed and human consumption, as well as for bread and other food products (Peña 2004). Moreover, triticale is a potential energy crop 
and source of biomass for bioethanol production (Wang et al. 1997). Triticale grows on poorer soils than wheat and slightly better soils than rye. In addition, the quality of the grain and its use is much better than that of rye. In certain types of marginal soils, triticale cultivars outperform the best wheat cultivars (FAO 2004). Thanks to such advantages, triticale is becoming increasingly competitive with other cereal species.

Poland is a very important region for progress in triticale breeding, since it is home to most cultivars, and numerous genetic studies on triticale have been carried out. The participation of Polish scientists in the cultivation of this grain is highly significant. The triticale cultivar Lasko was obtained by a team led by Tadeusz Wolski in 1968 (Ammar et al. 2004) and became the widest grown triticale in the world. In cold, wet environments, the highly productive winter triticale cultivars that were developed primarily in Poland are continuously expanding into most cereal-based crop management systems in Northern Europe (FAO 2015). In 1989, triticale occupied approximately 3.82 million hectares worldwide, while in Poland it accounted for approximately 1.4 million hectares, almost half of the world crop (FAO 2004). From 1987, Poland was the largest triticale producer, with a current production of 4.3 million tons of grain per year. CIMMYT centres in Mexico and Poland have the two most successful triticale breeding programmes in the world, initiated in 1964 and 1968 respectively. Several people have contributed to the success of triticale, and their work is summarized in several historic reviews (e.g., Varughese et al. 1996; Villareal et al. 1990). However, this species is gaining value throughout the world. Numerous studies on triticale and improvement of its yield and use have been conducted in the UK, Germany, Brazil, Australia, France, Portugal, Hungary and Turkey (FAO 2004; Losert et al. 2017). There are many good triticale cultivars on the market, but every year, new cultivars are introduced that are unquestionably superior in terms of use to the older cultivars. Our work examines new cultivars that have been bred in Poland. In Poland, the breeding process itself lasts eight years, followed by two years of research in the 
COBORU (Research Centre for Cultivar Testing) Post-Registration Variety Testing System (PVTS).

The new cultivars give farmers the opportunity to choose cultivars with the most favourable characteristics for the particular soil and climatic conditions of the farm. Despite the great interest in triticale both in Poland and around the world, there is a lack of research on the adaptation of cultivars and their contribution to crop yield (Losert et al. 2017). Current research on the adaptability and stability of cereals is poor, and there is no such work done in the field. The purpose of this study is to investigate the influence of cultivar, management, location and growing seasons on grain yield. In addition, we know from many studies that there is a large difference between years, and we wish to determine whether year is a factor that contributes to the highest grain yield. In addition, we planned to study the stability of triticale cultivars in different environments in eight growing seasons, determine whether there is any dependency between the eight seasons, and find the cause of the yield response to environmental conditions in a given growing season. We wish to establish whether it will be possible to group years that are similar in terms of the impact of individual effects on seed yield, and what causes this similarity.

\section{Material and methods}

\subsection{Trial dataset}

The triticale grain yield dataset used in this study represents a subset of results from the PVTS across the growing seasons from 2007/2008 to 2014/2015. This dataset contains eleven modern triticale cultivars evaluated across 58 locations (Table 1). All tested cultivars came from Polish breeding programmes. The field experiments were carried out using two levels of crop management intensity: moderate-input management (MIM) and conventional, high-input management (HIM). MIM did not include plant protection treatments, and standard fertilization was applied according to the soil needs of a given location. HIM was a high-input treatment designed to maximize yield. HIM included 
Table 1. Characteristics of 11 triticale cultivars: winter hardiness, resistance to fungal disease, protein content, and thousand grains weight

\begin{tabular}{ccccccc}
\hline \multirow{2}{*}{ Cultivars } & $\begin{array}{c}\text { Winter } \\
\text { hardiness }\end{array}$ & \multicolumn{2}{c}{ Resistance to fungal diseases } & powdery & brown & septoria \\
mildew & rust & $\begin{array}{c}\text { Protein } \\
\text { content }\end{array}$ & $\begin{array}{c}\text { Thousand } \\
\text { grains } \\
\text { weight }\end{array}$ \\
\hline Alekto & low & average & average & average & high & average \\
Algoso & low & average & average & average & average & high \\
Aliko & average & average & average & average & high & average \\
Baltiko & average & average & average & average & average & average \\
Grenado & very high & high & high & average & average & average \\
Leontino & average & low & high & average & high & high \\
Pigmej & low & high & high & high & average & average \\
Pizarro & low & high & high & high & high & average \\
Sorento & average & high & high & high & high & high \\
Todan & high & high & high & high & average & high \\
Trismart & high & high & average & average & high & high \\
\hline
\end{tabular}

high nitrogen fertilization (an additional $40 \mathrm{~kg} \mathrm{~N}$ per hectare) combined with frequent fungicide use, foliar fertilization and the application of a growth regulator. Foliar fertilization with liquid multicomponent preparations should be combined with the first and second fungicide treatment in HIM. Other cultivation and care treatments must be the same for both crop management levels. Detailed recommendations for some cultivation procedures may be different for crop management levels, but in line with the COBORU methodology. In this research, we used only data from the yields observed under HIM crop management, because growing of the tested cultivars under optimal conditions (as in the HIM crop management system) demonstrates their full genetic potential. Triticale cultivars can be classified in terms of straw length; they include short-straw cultivars such as Alekto, Baltiko, Grenado and Pigmej, and the traditional cultivars Algoso, Leontino, Pizarro, Sorento, Todan, and Trismart. Table 2 gives characteristics of the eleven cultivars studied. 
Table 2. The 58 tested locations used to evaluate 11 triticale cultivars across growing seasons from $2007 / 2008$ to $2014 / 2015$

\begin{tabular}{|c|c|c|c|c|c|}
\hline Location & Latitude & Longitude & Location & Latitude & Longitude \\
\hline Bakow & 50.97 & 18.32 & Marianowo & 53.21 & 22.10 \\
\hline Bezek & 51.11 & 23.15 & Mikolow & 50.11 & 18.54 \\
\hline Bialogard & 54.00 & 15.59 & Modliszewice & 51.20 & 20.37 \\
\hline Bobrowniki & 52.49 & 17.18 & Modzurow & 50.15 & 18.12 \\
\hline Boguchwala & 49.98 & 21.95 & Naroczyce & 51.52 & 16.41 \\
\hline Borowo & 52.12 & 16.79 & Nieznanice & 50.92 & 19.31 \\
\hline Choryn & 52.05 & 16.77 & Nowa Wies Ujska & 53.04 & 16.75 \\
\hline Chroberz & 50.85 & 19.96 & Nowy Lubliniec & 50.30 & 23.10 \\
\hline Chrzastowo & 53.17 & 17.58 & Palikije & 51.23 & 22.32 \\
\hline Cicibor & 52.05 & 23.07 & Pawlowice & 50.45 & 18.49 \\
\hline Czeslawice & 51.31 & 22.26 & Prusim & 53.78 & 15.43 \\
\hline Debina & 54.11 & 19.04 & Radostowo & 53.99 & 18.75 \\
\hline Dukla & 49.56 & 21.69 & Rarwino & 53.93 & 14.84 \\
\hline Falecin & 53.22 & 18.55 & Rychliki & 53.98 & 19.53 \\
\hline Glodowo & 52.83 & 19.24 & Seroczyn & 52.01 & 21.92 \\
\hline Glubczyce & 50.19 & 17.83 & Slupia & 52.21 & 17.22 \\
\hline Grodkowice & 49.97 & 20.26 & Sobiejuchy & 52.91 & 17.72 \\
\hline Jelenia Gora & 50.86 & 15.71 & Srem Wojtostwo & 52.06 & 17.02 \\
\hline Karzniczka & 54.38 & 17.14 & Strzelce & 52.31 & 19.40 \\
\hline Kaweczyn & 52.17 & 20.34 & Sulejow & 51.35 & 19.87 \\
\hline Kochcice & 50.71 & 18.68 & Swiebodzin & 52.24 & 15.55 \\
\hline Koscielna Wies & 51.48 & 18.01 & Tomaszow Boleslawiecki & 51.28 & 15.68 \\
\hline Kroscina Mala & 51.38 & 16.94 & Uhnin & 51.58 & 23.03 \\
\hline Krzyzewo & 53.03 & 22.76 & Wegrzce & 50.12 & 19.98 \\
\hline Laski & 51.80 & 21.14 & Winna Gora & 52.20 & 17.45 \\
\hline Losiow & 50.78 & 17.57 & Wloszczowa & 50.74 & 20.05 \\
\hline Luban & 54.12 & 18.16 & Wrocikowo & 53.53 & 22.28 \\
\hline Lucmierz & 52.12 & 19.08 & Wyczechy & 53.44 & 17.02 \\
\hline Malyszyn & 52.74 & 15.18 & Zamarte & 53.60 & 17.49 \\
\hline
\end{tabular}

The eight years studied (2007/2008-2014/2015) were diverse in terms of climatic conditions. The highest rainfall in Poland comes in the summer months 
of June-August, and is 2-3 times higher than in winter. On the other hand, there are spatial variations in rainfall trends across the country. Average precipitation in Poland is $600 \mathrm{~mm}$ per year. The highest precipitation - above $1000 \mathrm{~mm}-$ occurs in mountain areas, while the lowest - below $500 \mathrm{~mm}$ - occurs in the lowlands of the central part of the country, which lie in the so-called "rain shade". Large precipitation values are also recorded in upland areas, which receive an average of 600 to $750 \mathrm{~mm}$ of precipitation per year. In addition, the amount of precipitation decreases from west to east. The wettest years were 2007/2008, 2010/2011, 2012/2013 and 2014/2015, with most of the country, especially the southern part, being flooded in 2010/2011 and 2014/2015, although this did not affect the crop. There was an extremely dry growing season in 2013/2014, when during the summer drought occurred in most parts of the country. In the remaining vegetation seasons there were no anomalies and the rainfall was normal. Poland is characterized by the occurrence of snowfall in winter. The number of days with snowfall ranges from 30 in the central plains of Poland to over 100 in mountain areas. Exceptional in this respect were the seasons 2008/2009 and 2010/2011, when twice as much snow fell compared with the average. In turn, the number of days of snow cover ranges from 40 to 60 days per year. An exception is the highest mountain ranges, where the snow cover is over 200 days. However, differences in temperature distribution occur between years and parts of the country. Poland is located in a temperate climate zone with transitional characteristics. This transition occurs because, over the area of Poland, air masses with different characteristics are clustered, such as the mass of sea air (wet) flowing from the west from Western Europe (from the Atlantic) and continental (dry) air from the east from the vast land of Asia. The country's average annual air temperature is $6-8.5^{\circ} \mathrm{C}$. The warmest regions are southern and southwestern Poland (over $8.5^{\circ} \mathrm{C}$ ).

The warmest growing seasons were 2007/2008, 2010/2011 and 2013/2014. The lowest temperatures occur in the mountains, where they decrease with an increase in elevation (on average $0.6{ }^{\circ} \mathrm{C}$ per $100 \mathrm{~m}$ elevation), which affects 
climatic conditions. Outside mountain areas, the coldest region of the country is north-eastern Poland (approximately $6.5^{\circ} \mathrm{C}$ ), called the "Polish polar cold". The coldest growing season was in 2008/2009.

\subsection{Statistical analysis}

The analysis of the study dataset for triticale yield was performed using two linear mixed models (LMM). First, we tested the significance of all four factors $\mathrm{G}, \mathrm{M}, \mathrm{L}, \mathrm{Y}$ and their interactions, as shown below:

$\mathrm{X}_{i j k l}=\mathrm{m}+\mathrm{Y}_{i}+\mathrm{L}_{j}+\mathrm{YL}_{i j}+\mathrm{G}_{k}+\mathrm{GY}_{i k}+\mathrm{GL}_{j k}+\mathrm{GLY}_{i j k}+\mathrm{M}_{l}+\mathrm{MY}_{i l}+$ $\mathrm{ML}_{j l}+\mathrm{MLY}_{i j l}+\mathrm{GM}_{k l}+\mathrm{GMY}_{i k l}+\mathrm{GML}_{j k l}+\mathrm{GMLY}_{i j k l}$

where $\mathrm{X}_{i j k l}$ is the yield for the 4-factorial combination of the $i$-th year, the $j$-th $(j=1,2, \ldots, \mathrm{J})$ location, the $k$-th cultivar and the $l$-th crop management intensity; $\mathrm{m}$ is the general mean; $\mathrm{Y}_{i}$ is the random main effect of the $i$-th year; $\mathrm{L}_{j}$ is the fixed main effect of the $j$-th location; $\mathrm{G}_{k}$ is the random main effect of the $k$-th cultivar; $\mathrm{M}_{l}$ is the fixed main effect of the $l$-th crop management intensity; $\mathrm{YL}_{i j}$ is the random interaction effect of the $i$-th year and the $j$-th location; $\mathrm{GY}_{k i}$ is the random interaction effect of the $k$-th cultivar and the $i$-th year; $\mathrm{GL}_{k j}$ is the random interaction effect of the $k$-th cultivar and the $j$-th location; $\mathrm{MY}_{l i}$ is the random interaction effect of the $l$-th crop management intensity and the $i$-th year; $\mathrm{ML}_{l j}$ is the fixed interaction effect of the $l$-th crop management intensity and the $j$-th location; $\mathrm{GM}_{k l}$ is the random interaction effect of the $k$-th cultivar and the $l$-th crop management intensity; GLY $\mathrm{GLi}_{k j}$ is the random interaction effect of the $k$-th cultivar, the $j$-th location and the $i$-th year; $\mathrm{GMY}_{k l i}$ is the random interaction effect of the $k$-th cultivar, the $l$-th crop management intensity and the $i$-th year; $\mathrm{GML}_{k l j}$ is the random interaction effect of the $k$-th cultivar, the $l$ th crop management intensity and the $j$-th location; $\operatorname{MLY}_{l j i}$ is the random interaction effect of the $l$-th crop management intensity, the $j$-th location and the $i$-th year; and GMLY ${ }_{k l j i}$ is a random residual comprising the interaction effect of the $k$-th cultivar, the $l$-th crop management intensity, the $j$-th location, the $i$-th year, and the error term associated with mean $\mathrm{X}_{i j k l}$. 
Second, we tested the significance of the cultivar, crop management and location in each tested growing season separately. An analysis was then performed based on LMM as follows:

$$
X_{i j k l}=m+L_{j}+G_{k}+G L_{j k}+M_{l}+M L_{j l}+G M_{k l}+G M L_{j k l}
$$

where $\mathrm{X}_{j k l}$ is the yield for the 3-factorial combination of the $j$-th location, the $k$ th cultivar and the $l$-th crop management intensity; $\mathrm{GML}_{k l j}$ is a random residual comprising both the interaction effect of the $k$-th cultivar, the $l$-th crop management intensity and the $j$-th location and the error term associated with mean $\mathrm{X}_{j k l}$; other abbreviations are the same as in the first model (1).

The significance and impact of the main effects and interaction effects in this study are based on the variance components. The variance components for random effects were estimated using the restricted maximum likelihood (REML) method implemented in the ASReml-R package. The likelihood ratio test was used to evaluate the significance of calculated variance components.

\section{Results}

The variance components presented in Table 3 are based on model (1), taking into account the year effects. The greatest part of the yield variation was caused by the location effect: $38.29 \%$. These environmental effects are the most significant, as the year explains $7.28 \%$ of the variation and the location $\mathrm{x}$ year interaction explains $28.66 \%$ of the yield variation. Thus, the environmental effects of location, year and location $\mathrm{x}$ year explain $3 / 4$ of the total yield variation - approximately $74 \%$. Management also had a relatively strong influence on yield variability, with a main effect of approximately $10 \%$ of the total yield variation. The cultivar main effect explained only $0.44 \%$ of the total variation, while the location $\mathrm{x}$ year $\mathrm{x}$ cultivar effect accounted for $4.95 \%$ of the yield of triticale. This result demonstrates the uneven impact of the management level in different locations and/or years. To evaluate the different influences on yield from the individual main and interaction effects affected by 
environmental conditions (especially weather), their contributions were calculated for each year separately.

Table 3. Variance components from model (1) in percent of total variation in the Triticale PVTS dataset

\begin{tabular}{lcr}
\hline Source of Variation & component & $\%$ \\
\hline Management & 1.15 & 9.69 \\
Year & 0.86 & 7.29 \\
Cultivar & 0.05 & 0.45 \\
Year x Management & 0.40 & 3.37 \\
Cultivar x Management & 0.03 & 0.28 \\
Location & 4.53 & 38.29 \\
Year x Cultivar & 0.17 & 1.46 \\
Location x Management & 0.09 & 0.79 \\
Year x Cultivar x Management & 0.01 & 0.08 \\
Location x Year & 3.39 & 28.67 \\
Location x Cultivar & 0.15 & 1.23 \\
Location x Year x Management & 0.41 & 3,47 \\
Location x Cultivar x Management & 0.01 & 0.01 \\
Location x Year x Cultivar & 0.59 & 4.95 \\
Location x Management x Cultivar x Year & 0.01 & 0.01 \\
\hline
\end{tabular}

The influence of the main effects and interaction effects on triticale yield variation, in this study, is different in different growing seasons (Table 4). Over all growing seasons, the strongest influence on the yield of triticale comes from the location main effect. However, that influence shows great variation across growing seasons, with a range from 53.3\% in season 2013/2014 to $95.6 \%$ in season 2007/2008. The second important source of yield variability is crop management. This explains from approximately $1 \%$ of the total yield variation in $2007 / 2008$ to $28.3 \%$ in $2013 / 2014$. The relationship between the location and 
Table 4. Variance components in percent of total variation separately for studied growing seasons - model (2)

\begin{tabular}{lrrrrrrrr}
\hline \multirow{2}{*}{$\begin{array}{l}\text { Variance } \\
\text { components }\end{array}$} & $2007 /$ & $2008 /$ & $2009 /$ & $2010 /$ & $2011 /$ & $2012 /$ & $2013 /$ & $2014 /$ \\
& 2008 & 2009 & 2010 & 2011 & 2012 & 2013 & 2014 & 2015 \\
\hline Management & 0.91 & 12.94 & 7.26 & 7.12 & 6.49 & 23.52 & 28.32 & 18.05 \\
Cultivar & 1.85 & 2.45 & 0.75 & 3.20 & 3.32 & 2.53 & 1.66 & 2.98 \\
$\begin{array}{l}\text { Management x } \\
\text { Cultivar }\end{array}$ & 0.01 & 0.42 & 0.09 & 0.21 & 0.23 & 0.60 & 1.01 & 0.60 \\
$\begin{array}{l}\text { Location } \\
\text { Location x }\end{array}$ & 95.59 & 72.54 & 83.58 & 68.90 & 70.47 & 60.52 & 53.32 & 69.02 \\
$\begin{array}{l}\text { Management } \\
\text { Location x Cultivar }\end{array}$ & 1.03 & 3.39 & 3.08 & 5.99 & 6.22 & 7.82 & 5.81 & 4.82 \\
$\begin{array}{l}\text { Location x } \\
\text { Management x }\end{array}$ & 0.62 & 7.59 & 5.23 & 13.21 & 13.27 & 5.00 & 8.72 & 3.78 \\
Cultivar & 0.01 & 0.67 & 0,01 & 0.01 & 0.01 & 0.01 & 1.14 & 0.75 \\
\hline
\end{tabular}

management main effects is dependent on growing season. When location has a stronger influence on yield, the management main effect is lower. Conversely, when the management factor has a stronger influence on triticale yield, the effect of location is smaller. Cultivar main effects have the lowest influence on triticale yield variation. Additionally, cultivar main effects are characterized by low variability of variance components, ranging from $0.7 \%$ of the total yield variation in 2009/2010 to $3.3 \%$ in 2011/2012. The mean grain yield for growing seasons and for two crop management levels is shown in Figure 1.

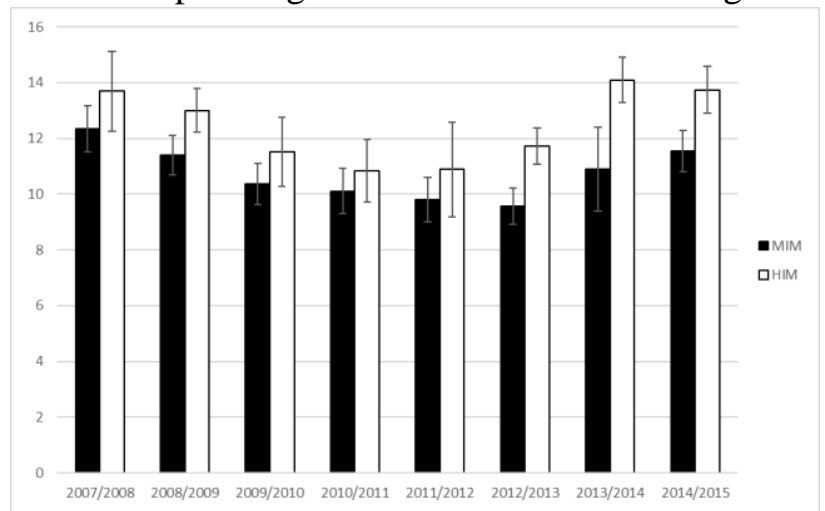

Figure 1. Mean grain yield for growing seasons for two crop management levels 
The interactions of particular factors have less influence than the studied main effects. Location $\mathrm{x}$ cultivar has the greatest influence on the yield of triticale compared with all other interactions. The percentage contribution of cultivar $x$ location interactions ranges from $0.62 \%$ in the 2007/2008 season to $13.27 \%$ for the $2011 / 2012$ season. In the $2007 / 2008$ season, only the local conditions had an impact on the grain yield. On the other hand, when cultivar $x$ location interactions explained more than $13 \%$ of the total variation, the location effect was over $70 \%$, but both the cultivar and management effects had a significant impact on grain yields compared with the remaining years. Thus, the right choice of cultivars and crop management intensity levels for the local conditions will have the effect of increasing grain yield. The management $\mathrm{x}$ location interaction was slightly lower than the cultivar $\mathrm{x}$ management interactions, ranging from $1.03 \%$ in $2007 / 2008$ to $7.82 \%$ in $2012 / 2013$. The location $\mathrm{x}$ management $\mathrm{x}$ cultivar triple interaction is the least significant interaction. In five of the eight analysed years, its contribution was $0 \%$. In the year of its highest contribution, 2013/2014, it was just over $1 \%$.

\section{Discussion}

Many researchers and breeders are interested in whether individual effects (main effects and interactions) have a significant impact on the value of an attribute such as grain yield. In this study we have indicated the participation of all four main factors and the interactions between them in determining the triticale crop. Of the four main effects, cultivar explained the smallest amount of variation in grain yield. This was similar in the analysis performed separately across years. There, three factors and their interactions were analysed. In the analysis carried out separately for eight growing seasons, it can be seen that although the contribution of cultivar is small in comparison with the other main factors, it is very stable. This means that regardless of the climatic and soil conditions in a given growing season, the amount of grain yield variation explained by cultivar is similar. Similar results have been obtained for other 
plant species, for example, in the studies of Temesgeri et al. (2015) with faba beans (Vicia faba L.) and Mohammadi et al. (2015) with durum wheat. The contribution of cultivar in these studies ranged from $2.5 \%$ to $5.3 \%$. Yield is influenced only slightly by cultivar, but to a large extent by the location effect. In the same studies, over $80 \%$ of all other factors were the predominant environmental effects. The aim of a number of multi-environmental experiments is to evaluate cultivars for conditions in environments at different levels of an additional factor. Such an additional factor may be management, abiotic stresses (e.g., stress related to drought) or biotic stresses (e.g., pests and diseases). In our work, the added factor was management intensity level. We have shown that the influence of the cultivar is smaller, that the environmental effects gain in importance, and that if the location effect is smaller, the management effect is more important for triticale grain yield. This is related to the climatic and soil conditions prevailing in a given year. Therefore, the adequate choice of management intensity level and monitoring of the impact of this factor on grain yield for several growing seasons is very important for progress in breeding. Many researchers also argue (Hammer et al. 2014) that optimal combinations of cultivar and management depend on the environment and seasons. In the shaping of the grain yield of triticale, one can notice a certain tendency in the influence of particular factors, particularly management, in different years. In extreme weather conditions, both with very large amounts of rainfall, even floods in the 2012/2013 and 2014/2015 seasons, and drought, as in the 2013/2014 season, when drought was recorded throughout the country, the importance of the management effect accounted for over a quarter of the impact on grain yield. Contrasting results were reported by Studnicki et al. (2016), who found that under unfavourable conditions of wheat cultivation, the importance of varieties and crop management influenced the yield variability, with quality characteristics being lower than in the environments with favourable soil conditions. Therefore, determining the yield response to an additional factor in different weather conditions prevailing in different years is very important. Piepho et al. (2014) claim that the selection of appropriate 
management is often the cause of growth in long-term crop yields. However, in the studies of Losert et al. (2017), the authors conclude that the trend of yield behaviour can be identified by observing the crop for several growing seasons. In addition, studies conducted separately over the years allow for the investigation of a heterogeneous adaptive response of cultivars to conditions in individual growing seasons, and produces a heterogeneous ranking of cultivars and the impact of an additional factor. In addition, thanks to such long-term research, it can be concluded that the grain yield and adaptive abilities of plants are very strongly dependent on the locality, but to a lesser extent on the conditions prevailing in the given growing seasons. Additionally, Piepho et al. (2014) recently demonstrated that the latter are thereby more suitable for obtaining estimates of the true genetic trend component, while this tends to be overestimated in long-term trial data analysis. Weather is a random factor that is independent and difficult to predict, which is why conclusions from longterm research can be used only as a guide, indicating a certain trend. For example, it cannot be unequivocally stated that the influence of the environment always has a dominant influence on yields. Liu et al. (2013) studied the variance components in cotton performance in two different periods, 1980-1994 and 1995-2009, and found interesting results across different years. In the first analysed period, cultivar accounted for $14.6 \%$ of the variation, and in the second it accounted for $42.4 \%$. A surprisingly high proportion of the variation may be explained by the species. In the case of cereals, this makes a much lower contribution to the yield. Based on the research, it can be concluded that the very large effect on the yield exerted by the individual studied factors in the long term allows us to illustrate trends in the effects of variance.

\section{Acknowledgments}

We would like to thank the Director of Development of Polish Official Variety Testing for providing data on the grain yield of the tested triticale cultivars used in this work. 


\section{REFERENCES}

Ammar K, Mergoum M., Rajaram S. (2004): The history and evolution of triticale. In: Mergoum M., Gómez-Macpherson H., eds. Triticale improvement and production. Rome: Food and Agriculture Organization of the United Nations: 1-10.

FAO Plant Production and Protection (2004): Triticale improvement and production. Paper 179. Roma.

FAO 2015. Statistical Yea0rbook (2015): World Food and Agriculture, Roma.

Hammer G.L., McLean G., Chapman G., Zheng B., Doherty A., Harrison M.T. , van Oosterom, E., Jordan, D. (2014): Crop design for specific adaptation in variable dryland production environments. Crop and Pasture Science 65(7): 614-626.

Liu S.M., Constable G.A., Reid P.E., Stiller W.N., Cullis B.R. (2013): The interactions between breeding and crop managements in improved cotton yield. Field Crop Res. 148: 49-60.

Losert D., Mauren H.P., Marulanda J.J.. Wurschum T. (2017): Phenotypic and genotypic analyses of diversity and breeding progress in European triticale (x Triticosecale Wittmark). Plant Breeding 136: 18-27.

Mohammadi R., Farsadfar E., Amri A. (2015): Interpreting genotype x environments interactions for grain yield of rainfed durum wheat in Iran. The Crop Journal 3: 526-535.

Varughese G., Pfeiffer W.H., Pena R.J. (1996): Triticale. A successful alternative crop. Cereal Foods World 41: 474-482.

Villareal R.L., Varughese G., Abdalla O.S. (1990): Advances in spring triticale breeding. Plant Breeding Rev. 8: 43.

Peña R.J., Mergoum M., Gómez-Macpherson H. (2004): Triticale improvement and production. Rome: Food and Agriculture Organization of the United Nations: 37-48.

Piepho H.P., Laiding F., Drobek T., Mayer U. (2014): Dissecting genetic and nongenetic sources of long-term yield trend German official variety trials. Theoretical Applied. Gen. 127: 1009-1018.

Studnicki M., Mądry W., Noras K., Wójcik-Gront E., Gacek E. (2016): Yield response of winter wheat cultivars to environments modeled by different variancecovariance structures in linear mixed models. Spanish Journal of Agricultural Research 14(2), e0703 http://dx.doi.org/10.5424/sjar/2016142-8737

Temesgeri T., Keneni G., Sefera T., Jarso M. (2015): Yield stability and relationships among stability parameters in faba bean (Vicia faba L.) genotypes. The Crop J. 3: 258-268.

Wang S., Thomas K.C., Ingledew W.M., Sosulski K., Sosulski F.W. (1997): Rye and triticale as feedstock for fuel ethanol production. Cereal Chemistry 74: 621-625. 